\title{
$\begin{array}{ll}\text { Research Square } & \text { Preprints are preliminary reports that have not undergone peer review. } \\ \text { They should not be considered conclusive, used to inform clinical practice, } \\ \text { or referenced by the media as validated information. }\end{array}$
}

\section{Per- and polyfluoroalkyl substances in groundwater of Thailand: Occurrence, source identification and spatial distribution}

\section{Chanidaporn Hongkachok}

Mahidol University Faculty of Engineering

Suwanna Boontanon ( $\nabla$ suwanna.boo@mahidol.ac.th)

Mahidol University Faculty of Engineering https://orcid.org/0000-0003-2118-4577

\section{Narin Boontanon}

Mahidol University

\section{Suratsawadee Sukeesarn}

Mahidol University Faculty of Engineering

\section{Chongrak Polprasert}

Thammasat University

Shigeo Fujii

Kyoto University: Kyoto Daigaku

\section{Research Article}

Keywords: Groundwater, Per- and polyfluoroalkyl substances, municipal waste disposal site, industrial waste disposal site, soil properties, sources identification

Posted Date: March 2nd, 2021

DOI: https://doi.org/10.21203/rs.3.rs-219670/v1

License: (c) (1) This work is licensed under a Creative Commons Attribution 4.0 International License. Read Full License 


\section{Abstract}

Per- and polyfluoroalkyl (PFAS) have the potential to leach down to the groundwater particularly in areas with potential source pollution such as landfills. The composition patterns of PFAS, distribution and soil characteristics significantly contribute to their source identification. The objectives of this study were: (1) to examine the levels of PFAS in Thailand groundwater, (2) to identify potential sources, and (3) to study the spatial distribution of PFAS. Groundwater samples were collected around municipal waste disposal sites (MWDS) and industrial waste disposal sites (IWDS). Seven PFAS were extracted by solid phase extraction technique and analyzed by high-performance liquid chromatography tandem mass spectrometer. Total PFAS in groundwater around the MWDSs varied from 1.68 to $7.75 \mathrm{ng} \mathrm{L}^{-1}$. The total PFAS in groundwater around the IWDS varied from 2.64 to $42.01 \mathrm{ng} \mathrm{L}^{-1}$. PFOA and PFOS were the most dominant compounds around the MWDS and IWDS areas. PFHxS was frequently observed in the groundwater around the IWDSs, suggesting that it has been used as a substitution of PFOS-based compounds due to it having a shorter chain length or resulting from degradation of fluorotelomers. In addition to source identification, the hierarchical cluster analysis showed that other than the waste disposal site, other factors or activities could have been involved. It was found that livestock farming and an abandoned pond very close to the groundwater well could have affected the levels of PFAS in the groundwater. Moreover, spatial distribution showed that besides the impact of waste sources, soil characteristics and interaction between negative charged PFAS and cation in the soil played an important role in the PFAS contamination in groundwater.

\section{Introduction}

Per- and polyfluoroalkyl substances (PFAS) are emerging contaminants which have been used in a wide range of manufacturing including semiconductors, coatings for paper food packaging and textiles, and aqueous fire-fighting foams (AFFF) (Prevedouros et al., 2006; Renner, 2001; Domingo et al., 2017; Martin et al., 2019; Langberg et al., 2020; Glüge et al., 2020; Wu et al., 2020). Because of their strong carbon and fluorine bonds and hydrophilic and lipophilic characteristics, they are extremely persistent, thermal and chemical durable as well as bioaccumulative (Buck et al., 2011; Niu et al., 2019; Foguth et al., 2020; Stoiber et al., 2020). In a differentiation of PFAS, perfluorooctane sulfonate (PFOS) and perfluorooctanoic acid (PFOA) have been under continual investigation globally in the environment, animal tissues, and human blood (Giesy \& Kannan, 2001; Kannan et al., 2004; Jantzen et al., 2016; Olsen et al., 2017; Awad et al., 2020).

Ever since then global public health and environmental concern involving PFAS have been increasing considerably, and their large-scale production and uses have been restricted. In Thailand, although the usage and imported amounts of PFAS are currently unknown, their occurrence has been investigated since 2007, and this investigation is being continuously carried out. The presence of PFAS in Thailand has been reported in numerous environments, consumer products, and other materials: river water, wastewater, raw water, tap water, bottled water, air, cosmetics, food packaging, and textiles (Boontanon et al., 2012; Keawmanee et al., 2015; Kunacheva, 2009a; Kunacheva et al., 2009b; Kunacheva et al., 2010; Pattanasuttichonlakul et al., 2014; Poothong et al., 2012; Shivakoti et al., 2010; Supreeyasunthorn et al., 2016; Vo et al., 2020; Shigei et al., 2020).

Groundwater is known as a precious fresh water resource and is being increasingly drawn upon in Thailand, particularly in rural areas where surface water is insufficient and polluted. Although groundwater is naturally purified by soil and deep-rock layers, nevertheless, groundwater pollution could be seriously affected by numerous sources of pollution. Furthermore, in Thailand large amounts of municipal and industrial refuse has been improperly disposed of due to lack of effective management and monitoring budgets. Several research studies have documented that one of potential sources of groundwater contamination could be landfill leachate derived from waste disposal sites. Landfill leachate can contain a wide range of compounds with environmental and human health concerns (Eggen et al., 2010; Brusseau et al., 2020; Menger et al., 2020). Levels of PFAS reported in landfill leachate were from the ng range up to several $\mu \mathrm{g}$ range in other countries (Benskin et al., 2012; Busch et al., 2010; Lang et al., 2017; Wei et al., 2019; Solo-Gabriele et al., 2020; Wang et al., 2020; Cui et al., 2020; Yong et al., 2020), while there is no data on the occurrence of PFAS in groundwater in Thailand. Therefore, this study aimed to determine PFAS levels in groundwater, identify expected potential sources of the contamination, and study their spatial

Page 2/16 
distribution. This study would be beneficial for understanding their contamination in groundwater, for providing information for further study, and for implementation of environmental standards and regulations.

\section{Materials And Methods \\ Standards and reagents}

Seven PFAS standards: perfluorohaptanoic acid (PFHpA), perfluorooctanoic acid (PFOA), perfluorononanoic acid (PFNA), perfluorodecanoic acid (PFDA), perfluoroundecanoic acid (PFUnA), perfluorohexane sulfonate (PFHxS), and perfluorooctane sulfonate (PFOS) were selected. High purity solvents: methanol HPLC grade (>99.99\%), methanol ACS grade, and acetonitrile HPLC grade (>99.8\%); and ammonium acetate (98\%) were purchased from Merck KGaA (Millipore, Germany). All the standard solutions were prepared in methanol HPLC grade. Ultrapure water used in chemical analysis was produced by a RiOs-DI® Water Purification System (Millipore, Germany).

\section{Sampling sites and sample collection}

The groundwater sampling points were chosen in three cities in Thailand, which are given in Fig. 1. The groundwater was collected from domestic groundwater wells nearby waste disposal sites in Bang Sai and Sena MWDS, Ayutthaya $(n=12)$, Nong Nae IWDS, and Chachoengsao $(n=4)$, which have been in continual operation, and Map Pai IWDS, Chonburi $(n=15)$, which has been completely closed. The samples were directly collected from faucets connected to the groundwater wells and pumping systems by using 1.5-L PET bottles, which were rinsed with methanol and dried prior to use. The containers were rinsed by the water samples three times to prepare the same conditions as the samples before collection. After sampling, the samples were stored in a cooler box and brought back to the Water Quality Analysis Laboratory, Mahidol University. The samples were filtered by GF/B glass filter. Glass bottles and glass equipment were avoided during the experiment due to the fact that target compounds may adhere to the glass in aqueous solutions. Teflon equipment was also avoided because interferences may be introduced to the samples of extracts (Hansen et al., 2002; Yamashita et al., 2004).

\section{Sample extraction and instrumental analysis}

PFAS were extracted by Solid Phase Extraction (SPE) technique. A $1500 \mathrm{~mL}$ of water sample was filtered by $1 \mu \mathrm{m}$ GF/B glass fiber filter and then loaded into PrecepC-Agri (C18) cartridges using concentrators at a flow rate of $10 \mathrm{~mL} / \mathrm{min}$. Before loading, the concentrators were washed by methanol at a flow rate of $10 \mathrm{~mL} / \mathrm{min}$ for $5 \mathrm{~min}$, followed by milli-Q water at a flow rate of $10 \mathrm{~mL} / \mathrm{min}$ for $10 \mathrm{~min}$ and then the cartridges were preconditioned by $10 \mathrm{~mL}$ of methanol, followed by 2 times of $10 \mathrm{~mL}$ milli$\mathrm{Q}$ water. After that, target analytes were eluted by $4 \mathrm{~mL}$ of methanol, followed by $2 \mathrm{~mL}$ of acetonitrile. Eluents were gently purged by nitrogen gas and reconstituted with $0.5 \mathrm{~mL}$ of $30 \%$ acetonitrile. Analysis of target PFAS was performed by using Agilent 1200SL HPLC coupled with Agilent 6400 MS/MS, in negative mode of electrospray ionization (ESI). Mobile phases consisted of (A) $10 \mathrm{mM}$ ammonium acetate in ultrapure water and (B) 100\% acetonitrile (HPLC/MS grade). The initial mobile phase was $30 \%$ acetonitrile, and then ramped up to $60 \%$ acetonitrile at 16.5 minutes, and kept for 3.5 minutes. At 23 minutes, acetonitrile went up to $70 \%$, and then linearly ramped up from $70-90 \%$ at 26 minutes. After that, the mobile phase gradient ramped down again to $30 \%$ acetonitrile for 4 minutes. The total running time was 30 minutes. The analytical parameters by HPLC-MS/MS analysis are given in Table 1. 
Table 1

Analytical parameters by HPLC-MS/MS analysis and recovery rates (\%) of PFAS in spiked water samples

\begin{tabular}{|c|c|c|c|c|c|c|c|}
\hline \multirow[t]{2}{*}{ Compound } & \multirow{2}{*}{$\begin{array}{l}\text { Parent ion } \\
(\mathrm{m} / \mathrm{z})\end{array}$} & \multirow{2}{*}{$\begin{array}{l}\text { Daughter ion } \\
(\mathrm{m} / \mathrm{z})\end{array}$} & \multirow{2}{*}{$\begin{array}{l}\text { Retention time } \\
\text { (min) }\end{array}$} & \multirow{2}{*}{$\begin{array}{l}\mathrm{LOD}^{\mathrm{a}} \\
\text { (ng L- } \\
{ }^{1} \text { ) }\end{array}$} & \multirow{2}{*}{$\begin{array}{l}\mathrm{LOQ}^{\mathrm{b}} \\
\text { (ng L- } \\
\left.{ }^{1}\right)\end{array}$} & \multicolumn{2}{|c|}{ Recovery $(n=5)$} \\
\hline & & & & & & Range $^{c}$ & Mean $^{c}$ \\
\hline PFHpA & 363 & 319 & 10.6 & 0.13 & 0.45 & $\begin{array}{l}92.19- \\
99.38\end{array}$ & 95.90 \\
\hline PFOA & 413 & 369 & 13.9 & 0.11 & 0.37 & $\begin{array}{l}99.77- \\
118.56\end{array}$ & 106.94 \\
\hline PFNA & 463 & 419 & 16.4 & 0.09 & 0.30 & $\begin{array}{l}97.18- \\
101.94\end{array}$ & 99.02 \\
\hline PFDA & 513 & 469 & 20.7 & 0.07 & 0.23 & $\begin{array}{l}87.65- \\
94.20\end{array}$ & 91.36 \\
\hline PFUnA & 563 & 519 & 22.8 & 0.07 & 0.23 & $\begin{array}{l}73.26- \\
92.02\end{array}$ & 83.82 \\
\hline PFHxS & 399 & 80 & 15.0 & 0.02 & 0.07 & $\begin{array}{l}99.73- \\
103.80\end{array}$ & 100.87 \\
\hline PFOS & 499 & 80 & 22.2 & 0.11 & 0.37 & $\begin{array}{l}88.04- \\
99.72\end{array}$ & 93.16 \\
\hline \multicolumn{8}{|c|}{ a Limit of detection } \\
\hline \multicolumn{8}{|c|}{${ }^{b}$ Limit of quantification } \\
\hline Ten nanc & per liter & PFAS stand & ed into & $s$ & & & \\
\hline
\end{tabular}

\section{Quality control}

Five points of a calibration curve comprising 0.1 to $10 \mu \mathrm{gL}^{-}$were prepared with the determination coefficients $\left(\mathrm{R}^{2}\right)$ more than 0.999. Limit of detection (LOD) and limit of quantification (LOQ) of the measurement method were defined as the concentration with signal-to-noise ratios (S/N) equal to 3:1 and 10:1, respectively (Yamashita et al., 2004). The recoveries of the seven PFAS in groundwater matrix were evaluated by spiking $10 \mu \mathrm{L} \mathrm{L}^{-}$of each of the PFAS standards into one liter of the sample. A blank sample which used ultrapure water was prepared and the same procedure as the spike samples was followed. The recovery rates of target compounds are shown in Table 1.

\section{Statistical analysis}

Source identification was evaluated by hierarchical cluster analysis using IBM ${ }^{\circledR}$ SPSS $®$ Statistics for Windows 20 . The Ward's method (squared Euclidean distance) was used as an agglomeration technique. Cluster analysis is considered as the multivariate statistical method for source apportionment of organic pollutants (Xiao et al., 2012) and normally is used to identify groups of individuals or objects that are similar to each other. Similarity patterns of PFAS were agglomerated in the same cluster. Before the analysis, concentrations higher than or equal to limit of detection (LOD) but less than limit of quantification were assigned with a concentration twice that of the LOD, and those at or below the LOD were assigned as zero (Yao et al., 2014).

\section{Results And Discussion}

Concentrations of PFAS in groundwater around the municipal waste disposal sites (MWDSs) and the industrial waste disposal sites (IWDSs) and their distribution patterns 
The concentrations of PFAS in all groundwater samples around the MWDSs and the IWDSs are summarized in Table 2. Six target compounds: PFOS, PFOA, PFHpA, PFNA, PFUnA, and PFHxS were detected in all groundwater samples collected around Bang Sai MWDS, while PFDA was undetectable from any of the groundwater samples around Bang Sai MWDS. Five of seven PFAS: PFOA, PFOS, PFNA, PFUnA, PFHpA were observed in the groundwater around Sena MWDS, whereas PFDA and PFHxS were absent. The concentrations of total PFAS in groundwater around both MWDSs ranged from 1.68 to $7.75 \mathrm{ng} \mathrm{L}-1$. Among them, PFOS was the most abundant one in the groundwater around Bang Chai MWDS, followed by PFOA, PFHpA, PFNA, PFUnA, and PFHxS, respectively, while PFOA was dominant in the samples around Sena MWDS. It could be noticed that the PFAS distribution pattern varied among the areas although they were surrounded by the MWDS. This could be affected by rain input and waste arrangement variations within a waste disposal site, which may impact the initial leachate components before reaching the groundwater (Eschauzier et al., 2013; Hepburn et al., 2019; Yong et al., 2020). The levels of total PFAS in the groundwater around Nong Nae IWDSs and Map Pai IWDS, where illegal industrial waste dumping has occurred, varied from 4.43 to $10.80 \mathrm{ng} \mathrm{L}^{-1}$ and 2.64 to $42.01 \mathrm{ng} \mathrm{L}^{-1}$, respectively. It could be seen that the concentrations were much higher than those around MWDS. Four target compounds: PFOA, PFOS, PFHxS, and PFHpA were measured in the samples around Nong Nae IWDSs, while all PFAS were detected in those around Map Pai IWDS. Among the target compounds found the dominant ones were PFOA and PFOS, which is similar to those found in other countries. It could be confirmed that PFOS and PFOA are still being used in industrial processes or are a part of chemicals used in consumer products. Importantly, PFHxS was frequently observed in the groundwater samples around two IWDSs, which might indicate that it has been used as a substitution of PFOS-based compounds due to it having a shorter chain length, or having resulted from degradation of fluorotelomers. However, PFHxS may not be a good alternative because it has been determined that it has long average half-lives (Li et al., 2018) and much more liver toxicity than PFOS (Lloyd-Smith \& Senjen, 2015). Therefore, this could be a greater human health concern if the water is used as a drinking water resource. In addition to total PFAS concentrations around the IWDSs, it could be seen that total PFAS around Map Pai IWDS were noticeably higher than those around Nong Nae IWDS; it might be caused by other factors besides sources, such as the effect of soil components which are described further. 
Table 2

PFAS concentration (ng $\mathrm{L}^{-1}$ ) in groundwater around the municipal waste disposal sites and the industrial waste disposal sites

\begin{tabular}{|c|c|c|c|c|c|c|c|}
\hline Sampling location & PFHpA & PFOA & PFNA & PFDA & PFUnA & PFHXS & PFOS \\
\hline \multicolumn{8}{|l|}{ Bang Sai MWDS } \\
\hline MW_BS01 & $<\mathrm{LOQ}^{\mathrm{a}}$ & 0.71 & N.D. ${ }^{b}$ & N.D. ${ }^{b}$ & N.D. ${ }^{b}$ & $<\mathrm{LOQ}^{\mathrm{a}}$ & 2.54 \\
\hline MW_BS02 & $<\mathrm{LOQ}^{\mathrm{a}}$ & 1.33 & $<\mathrm{LOQ}^{\mathrm{a}}$ & N.D. ${ }^{b}$ & $<\mathrm{LOQ}^{\mathrm{a}}$ & 0.07 & 3.15 \\
\hline MW_BS03 & 0.54 & 1.23 & $<\mathrm{LOQ}^{\mathrm{a}}$ & N.D. ${ }^{b}$ & $<\mathrm{LOQ}^{\mathrm{a}}$ & N.D. ${ }^{b}$ & 0.87 \\
\hline MW_BS04 & $<\mathrm{LOQ}^{\mathrm{a}}$ & 0.65 & 0.30 & $<\mathrm{LOQ}^{\mathrm{a}}$ & 0.29 & $<\mathrm{LOQ}^{\mathrm{a}}$ & 1.06 \\
\hline \multicolumn{8}{|l|}{ Sena MWDS } \\
\hline MW_SN01 & $<\mathrm{LOQ}^{\mathrm{a}}$ & 3.89 & 0.80 & $<\mathrm{LOQ}^{\mathrm{a}}$ & 0.40 & $<\mathrm{LOQ}^{\mathrm{a}}$ & 0.58 \\
\hline MW_SN02 & $<\mathrm{LOQ}^{\mathrm{a}}$ & 1.19 & 0.40 & N.D. ${ }^{b}$ & 0.29 & $<\mathrm{LOQ}^{\mathrm{a}}$ & $<\mathrm{LOQ}^{\mathrm{a}}$ \\
\hline MW_SN03 & $<\mathrm{LOQ}^{\mathrm{a}}$ & 1.55 & 0.15 & N.D. ${ }^{b}$ & $<\mathrm{LOQ}^{\mathrm{a}}$ & $<\mathrm{LOQ}^{\mathrm{a}}$ & 1.25 \\
\hline MW_SN04 & 0.58 & 3.76 & $<\mathrm{LOQ}^{\mathrm{a}}$ & N.D. ${ }^{b}$ & $<\mathrm{LOQ}^{\mathrm{a}}$ & $<\mathrm{LOQ}^{\mathrm{a}}$ & 0.71 \\
\hline MW_SN05 & 0.91 & 2.07 & $<\mathrm{LOQ}^{\mathrm{a}}$ & N.D. ${ }^{b}$ & $<\mathrm{LOQ}^{\mathrm{a}}$ & $<\mathrm{LOQ}^{\mathrm{a}}$ & 1.27 \\
\hline MW_SN06 & $<\mathrm{LOQ}^{\mathrm{a}}$ & 1.09 & 0.40 & N.D. ${ }^{b}$ & 0.34 & N.D. ${ }^{b}$ & 1.18 \\
\hline MW_SN07 & $<\mathrm{LOQ}^{\mathrm{a}}$ & 6.22 & 0.36 & $<\mathrm{LOQ}^{\mathrm{a}}$ & 0.49 & $<\mathrm{LOQ}^{\mathrm{a}}$ & 0.68 \\
\hline MW_SN08 & $<\mathrm{LOQ}^{\mathrm{a}}$ & 0.97 & 0.36 & N.D. ${ }^{b}$ & 0.34 & $<\mathrm{LOQ}^{\mathrm{a}}$ & $<\mathrm{LOQ}^{\mathrm{a}}$ \\
\hline \multicolumn{8}{|l|}{ Nong Nae IWDS } \\
\hline IW_NN01 & $<\mathrm{LOQ}^{\mathrm{a}}$ & 7.32 & $<\mathrm{LOQ}^{\mathrm{a}}$ & N.D. ${ }^{b}$ & N.D. ${ }^{b}$ & 0.39 & 3.08 \\
\hline IW_NN02 & $<\mathrm{LOQ}^{\mathrm{a}}$ & 2.21 & $<\mathrm{LOQ}^{\mathrm{a}}$ & N.D. ${ }^{b}$ & N.D. ${ }^{b}$ & 0.98 & 1.89 \\
\hline IW_NN03 & $<\mathrm{LOQ}^{\mathrm{a}}$ & 2.16 & N.D. ${ }^{b}$ & N.D. ${ }^{b}$ & $<\mathrm{LOQ}^{\mathrm{a}}$ & 0.20 & 2.08 \\
\hline IW_NN04 & 1.98 & 2.26 & N.D. ${ }^{b}$ & N.D. ${ }^{b}$ & N.D. ${ }^{b}$ & 0.12 & 1.39 \\
\hline \multicolumn{8}{|l|}{ Map Pai IWDS } \\
\hline IW_MP01 & $<\mathrm{LOQ}^{\mathrm{a}}$ & 20.11 & 0.39 & N.D. ${ }^{b}$ & 0.33 & 0.17 & 3.00 \\
\hline IW_MP02 & 1.97 & 7.90 & 0.43 & $<\mathrm{LOQ}^{\mathrm{a}}$ & $<\mathrm{LOQ}^{\mathrm{a}}$ & 0.13 & 1.81 \\
\hline IW_ MP03 & N.D. & 24.31 & 0.31 & $<\mathrm{LOQ}^{\mathrm{a}}$ & 0.47 & 0.14 & 3.33 \\
\hline IW_MP04 & $<\mathrm{LOQ}^{\mathrm{a}}$ & 0.83 & $<\mathrm{LOQ}^{\mathrm{a}}$ & $<\mathrm{LOQ}^{\mathrm{a}}$ & 0.27 & $<\mathrm{LOQ}^{\mathrm{a}}$ & 1.53 \\
\hline IW_MP05 & 0.66 & 10.22 & $<\mathrm{LOQ}^{\mathrm{a}}$ & $<\mathrm{LOQ}^{\mathrm{a}}$ & 0.24 & N.D. ${ }^{b}$ & 1.85 \\
\hline IW_MP06 & 1.42 & 4.38 & 1.58 & 0.61 & 0.24 & 0.15 & 2.88 \\
\hline
\end{tabular}

a $<$ LOQ refers to values less than limit of quantification

${ }^{b}$ N.D. refers to not detected 


\begin{tabular}{|c|c|c|c|c|c|c|c|}
\hline Sampling location & PFHpA & PFOA & PFNA & PFDA & PFUnA & PFHxS & PFOS \\
\hline IW_MP07 & 1.76 & 8.91 & 2.14 & 1.25 & $<\mathrm{LOQ}^{\mathrm{a}}$ & 3.73 & 13.84 \\
\hline IW_MP08 & N.D. & 0.80 & $<\mathrm{LOQ}^{\mathrm{a}}$ & $<\mathrm{LOQ}^{\mathrm{a}}$ & 0.26 & $<\mathrm{LOQ}^{\mathrm{a}}$ & 2.33 \\
\hline IW_ MP09 & $<\mathrm{LOQ}^{\mathrm{a}}$ & 24.57 & 0.45 & $<\mathrm{LOQ}^{\mathrm{a}}$ & 0.73 & N.D. ${ }^{b}$ & 3.87 \\
\hline IW_ MP10 & 0.59 & 34.96 & 1.22 & N.D. ${ }^{b}$ & 0.28 & 0.12 & 3.13 \\
\hline IW_MP11 & 1.34 & 5.71 & 1.45 & 0.82 & $<\mathrm{LOQ}^{\mathrm{a}}$ & 2.54 & 8.21 \\
\hline IW_ MP12 & N.D. ${ }^{b}$ & 17.82 & $<\mathrm{LOQ}^{\mathrm{a}}$ & $<\mathrm{LOQ}^{\mathrm{a}}$ & 1.39 & 0.35 & 8.17 \\
\hline IW_MP13 & 0.59 & 24.35 & $<\mathrm{LOQ}^{\mathrm{a}}$ & N.D. ${ }^{b}$ & 0.24 & $<\mathrm{LOQ}^{\mathrm{a}}$ & 5.61 \\
\hline IW_MP14 & 0.92 & 13.97 & 0.46 & 0.26 & $<\mathrm{LOQ}^{\mathrm{a}}$ & 0.52 & 25.88 \\
\hline IW_MP15 & 1.51 & 20.37 & 1.56 & $<\mathrm{LOQ}^{\mathrm{a}}$ & 0.45 & 0.09 & 3.99 \\
\hline \multicolumn{8}{|c|}{ a $<$ LOQ refers to values less than limit of quantification } \\
\hline${ }^{b}$ N.D. refers to no & ected & & & & & & \\
\hline
\end{tabular}

\section{Potential source identification}

The possible sources of PFAS were primarily classified by a hierarchical cluster analysis using IBM ${ }^{\circledR}$ SPSS ${ }^{\circledR}$ Statistics for Windows 20, based on analysis of their distribution patterns. The PFAS distribution patterns could be categorized into 3 clusters. The dendrogram result from the hierarchical cluster analysis of all groundwater samples is presented in Fig. 2.

Most groundwater samples around Bang Chai MWDS, Sena MWDS and Nong Nae IWDS were classified into cluster 1, which are surrounded by villages in rural areas. Although Nong Nae IWDS was represented as an industrial waste site category, the concentrations found in this area were classified into the same group with those around the municipal waste disposal sites. It should be remarked that other than types of waste source, other factors may be involved.

In clusters 2, three wells: IW_CB07, IW_CB11 and IW_CB14 were classified in the same group. This cluster presented unique PFAS distribution patterns, with PFOS being the most predominant substance found, followed by PFOA, PFHxS, PFNA, PFHpA, and PFDA. Surprisingly, these wells are quite far from Map Pai IWDS by $2.15 \mathrm{~km}, 1.5 \mathrm{~km}$, and $3.4 \mathrm{~km}$, respectively, but the concentrations were high. This might be caused by other potential sources, because IW_CB07 and IW_CB14 are very close to large abandoned ponds, and IW_CB11 is next to a pig farm. A map of these locations is presented in Fig. 2. It was difficult to pinpoint the pig farm as a potential source of contamination, because the contamination of PFAS is in animal feed, and the absorption and elimination of PFAS from animals especially pigs is not commonly reported, but wastewater from the livestock also could not be ignored. Lai et al. (2016) reported that wastewater from livestock industries are consider to be potential contamination sources of PFAS in Kinmen Lake, Taiwan. Therefore, it is suspected that the pig farm might be a potential source of PFAS contamination in sampling point IW_CB11, especially if there has been no appropriate wastewater or pig manure management. In the case of well number IW_CB07 and IW_CB14, the potential source of PFAS contamination could not be easily identified because the use of the large abandoned ponds could not be determined.

Clusters 5 and 6 contained most of the groundwater samples collected around Map Phai IWDS. A similar pattern was observed in clusters 5 and cluster 6 , in which PFOA was the most abundant followed by PFOS; the total PFAS concentrations in cluster 6 were obviously higher than for those in cluster 5 . The greatest concentration was quantified in the groundwater samples around Map Phai IWDS, which is in an industrialized area. Consistent with previous studies, PFAS were detected in industrialized or urbanized areas more than rural areas due to the presence of industrial activity (Wang et al., 2012; Chen et 
al., 2016). It should be remarked that the groundwater samples collected around both Nong Nae IWDSs, Chachoengsao and Map Phai IWDS, Chonburi were classified into different clusters, although they were representing IWDS. Therefore, their contamination and transportation might involve other factors besides the sources, which is discussed in the next section.

\section{Spatial distribution of PFAS in groundwater around the MWDSs and the IWDSs}

Regarding the results that have been discussed previously, it is clear that high concentrations of PFAS were detected in groundwater around the IWDSs, indicating that IWDSs play a significant role in the contamination of groundwater. However, the difference in PFAS levels in groundwater around Nong Nae IWDSs and Map Pai IWDSs were remarkable, even though they both represent similar sources of contamination. As mentioned previously, they might very well be affected by other factors. Therefore, study on the horizontal distribution of PFAS could illustrate effecting factors and their possible behaviors. Horizontal distribution was analyzed with geostatistical data (soil map) which was derived from the Land Development Department (LDD) of Thailand. In order to study the horizontal distribution, the data were analyzed using ArcGIS 10.1.

From Fig. $3(a, b)$, it can be noticed that the soil series in the Ayutthaya area where the sampling points are located is comprised of soil series named Ayutthaya (Ay) and Sena (Se). The Ay and Se soil series mostly consist of clay, so the main physical property is very low water permeability; in addition, major chemical properties are high acidity (pH 5.5 to 6 and 4 to 5.5 , respectively), and high cation exchange capacity (CEC) (LDD, 2010). It could be assumed that low PFAS concentrations in groundwater around the MWDSs might result from PFAS interaction with cation, which is consistent with the study reported by Xiao et al. (2015). In addition, Wang and Shih (2011) also reported that adsorption increases when pH decreases, they also found that $\mathrm{Ca}^{2+}$ and $\mathrm{Mg}^{2+}$ can form bridges with PFOA anions and PFOS can be bridged by $\mathrm{Ca}^{2+}$. Therefore, adsorption seems to be the main mechanism of PFAS contamination in these areas.

In the case of the PFAS concentration around the IWDSs, the concentration and their distribution patterns plotted with soil series in the areas are presented in Fig. 4 (a, b). It can be observed that PFAS concentration in groundwater around Nong Nae IWDSs was quite lower than those around Map Pai IWDS. This might be because these two areas consist of different soil series and soil properties. The soil series, named Klaeng (KI) and Don Rai (Dr), are soil series around Nong Nae IWDSs where the sampling points are located, whereas the soil series named Ban Bueng (Bbg) and Chonburi $(\mathrm{Cb})$ are soil series around Map Pai IWDS where the sampling points are located. The $\mathrm{KI}$ and $\mathrm{Dr}$ soil series contain moderate CEC, low water permeability, and $\mathrm{pH}$ of $4.5-6.4$ which is similar to the soil properties in the Ayutthaya areas. In contrast, low CEC, high water permeability, and $\mathrm{pH}$ of 5.5-8.5 were reported for $\mathrm{Bbg}$ and $\mathrm{Cb}$ soil series (LDD, 2010). Therefore, water permeability and the interaction of a negative charged form of PFAS with level of CEC in the soil most likely play an important role in the distribution of PFAS contamination.

\section{Conclusions}

There was variability in the distribution of PFAS in groundwater around the MWDSs and the IWDSs. PFAS were quantified in all groundwater samples. Total PFAS varied from 1.68 to $7.75 \mathrm{ng} \mathrm{L}^{-1}$ and 2.64 to $42.01 \mathrm{ng} \mathrm{L}^{-1}$ around MWDSs and IWDSs, respectively. Perfluorooctanoic acid (PFOA) and perfluorooctane sulfonate (PFOS) were the most dominant ones found in all samples. The occurrences of PFAS in groundwater around IWDSs were significantly higher than those around MWDSs, indicating more PFAS are intensively released from IWDSs. In terms of potential sources identification, it was performed by hierarchical cluster analysis. Classification of groundwater samples was based not only on total concentrations, but also on similar PFAS composition patterns. It should be remarked that not only direct sources of contamination influence the PFAS contamination, but other factors could have been involved. Besides the impact of sources, interaction between soil characteristics and PFAS properties plays an important role in PFAS contamination in groundwater. Additionally, a deep clay layer which is a major soil characteristic around the two MWDSs in Ayutthaya and Nong Nae IWDSs in Chachoengsao, can protect the aquifer, reduce movement, and adsorb the contaminants better than the sandy soil found around Map Pai IWDS, Chonburi. Moreover, further study related to movement of PFAS in the soil column is recommended in order to illustrate and

Page 8/16 
confirm their transportation mechanism. In conclusion, we firmly conclude that waste disposal site leachate could be a significant source of PFAS in Thailand groundwater.

\section{Declarations}

\section{Acknowledgements}

This study was supported by research funding from the Thailand Research Fund (TRF) RSA5880046.

\section{Author contribution}

Chanidaporn Hongkachok: material preparation, sample collection, sample analysis, data analysis, and writing the original manuscript. Suwanna Kitpati Boontanon: funding acquisition, filed investigation, data analysis, review and editing. Narin Boontanon: method optimization, review and editing. Suratsawadee Sukeesarn: sample analysis and data analysis. Chongrak Polprasert and Shigeo Fujii: review, editing and supervision.

Data Availability The data and materials of this study will be available from the corresponding author on reasonable request.

Ethics approval This manuscript has not been published or presented elsewhere in part or in entirety.

Consent to participate Not applicable

Consent for publication All authors agreed to publish this article in Environmental Science and Pollution Research.

Competing interests The authors declare no competing interests.

\section{References}

3M. (2000). Sulfonated Perfluorochemicals in the. Environment: Sources, Dispersion, Fate and Effects (OPPT2002-00430005). Retrieved from

https://yosemite.epa.gov/oppts/epatscat8.nsf/by+Service/73D8146F6A546EDD85257AF5004FAC94/\$File/89(811779X).pdf

Benskin, J. P., Li, B., Ikonomou, M. G., Grace, J. R., \& Li, L. Y. (2012). Per-and polyfluoroalkyl substances in landfill leachate: patterns, time trends, and sources. Environmental Science \& Technology, 46(21), 11532-11540.

Boontanon, S. K., Kunacheva, C., Boontanon, N., Musirat, N., Fujii, S., \& Tanaka, S. (2012). Occurrence of perfluorooctane sulfonate in the water environment of Bangkok, Thailand. Journal of Environmental Engineering, 139(4), 588-593.

Brusseau ML, Anderson RH, Guo B. PFAS concentrations in soils: Background levels versus contaminated sites. Science of the Total Environment. 2020 Oct 20;740:140017.

Buck, R. C., Franklin, J., Berger, U., Conder, J. M., Cousins, I. T., De Voogt, P., Jensen, A. A., Kannan, K., Mabury, S. A., \& van Leeuwen, S. P. (2011). Perfluoroalkyl and polyfluoroalkyl substances in the environment: terminology, classification, and origins. Integrated environmental assessment and management, 7(4), 513-541.

Busch, J., Ahrens, L., Sturm, R., \& Ebinghaus, R. (2010). Polyfluoroalkyl compounds in landfill leachates. Environmental Pollution, 158(5), 1467-1471.

Chen S, Jiao XC, Gai N, Li XJ, Wang XC, Lu GH, Piao HT, Rao Z, Yang YL. Perfluorinated compounds in soil, surface water, and groundwater from rural areas in eastern China. Environmental pollution. 2016 Apr 1;211:124-31.

Cui D, Li X, Quinete N. Occurrence, fate, sources and toxicity of PFAS: What we know so far in Florida and major gaps. TrAC Trends in Analytical Chemistry. 2020 Jul 3:115976. 
Domingo JL, Nadal M. Per-and polyfluoroalkyl substances (PFASs) in food and human dietary intake: a review of the recent scientific literature. Journal of agricultural and food chemistry. 2017 Jan 25;65(3):533-43.

Eggen, T., Moeder, M., \& Arukwe, A. (2010). Municipal landfill leachates: a significant source for new and emerging pollutants. Science of the Total Environment, 408(21), 5147-5157.

Eschauzier, C., Raat, K. J., Stuyfzand, P. J., \& De Voogt, P. (2013). Perfluorinated alkylated acids in groundwater and drinking water: Identification, origin and mobility. Science of the Total Environment, 458, 477-485.

Foguth RM, Hoskins TD, Clark GC, Nelson M, Flynn RW, de Perre C, Hoverman JT, Lee LS, Sepúlveda MS, Cannon JR. Single and mixture per-and polyfluoroalkyl substances accumulate in developing Northern leopard frog brains and produce complex neurotransmission alterations. Neurotoxicology and teratology. 2020 Sep 1;81:106907.

Giesy, J. P., \& Kannan, K. (2001). Global Distribution of Perfluorooctane Sulfonate in Wildlife. Environmental Science \& Technology, 35(7), 1339-1342. doi:10.1021/es001834k

Glüge J, Scheringer M, Cousins IT, DeWitt JC, Goldenman G, Herzke D, Lohmann R, Ng CA, Trier X, Wang Z. An overview of the uses of per-and polyfluoroalkyl substances (PFAS). Environmental Science: Processes \& Impacts. 2020;22(12):2345-73.

Hansen, K. J., Johnson, H., Eldridge, J., Butenhoff, J., \& Dick, L. (2002). Quantitative characterization of trace levels of PFOS and PFOA in the Tennessee River. Environmental Science \& Technology, 36(8), 1681-1685.

Hepburn E, Madden C, Szabo D, Coggan TL, Clarke B, Currell M. Contamination of groundwater with per-and polyfluoroalkyl substances (PFAS) from legacy landfills in an urban re-development precinct. Environmental Pollution. 2019 May 1;248:10113.

Jantzen CE, Annunziato KM, Cooper KR. Behavioral, morphometric, and gene expression effects in adult zebrafish (Danio rerio) embryonically exposed to PFOA, PFOS, and PFNA. Aquatic toxicology. 2016 Nov 1;180:123-30.

Kannan, K., Corsolini, S., Falandysz, J., Fillmann, G., Kumar, K. S., Loganathan, B. G., Mohd, M. A., Olivero, J., Wouwe, N. V., \& Yang, J. H. (2004). Perfluorooctanesulfonate and related fluorochemicals in human blood from several countries.

Environmental Science \& Technology, 38(17), 4489-4495.

Keawmanee, S., Boontanon, S. K., \& Boontanon, N. (2015). Method development and initial results of testing for perfluorooctane sulfonate (PFOS) and perfluorooctanoic acid (PFOA) in waterproof sunscreens. Environmental Engineering Research, 20(2), 127-132.

Kjølholt, J., Jensen, A. A., \& Warming, M. (2015). Short-chain Polyfluoroalkyl Substances (PFAS) (1707). Retrieved from The Danish Environmental Protection Agency, Copenhagen ,Denmark: https://www2.mst.dk/Udgiv/publications/2015/05/978-8793352-15-5.pdf

Kunacheva, C. (2009a). Study on Contamination of Perfluorinated Compounds (PFCs) in Water Environment and Industrial Wastewater in Thailand. Retrieved from Graduate School of Engineering, Kyoto University, Kyoto, Japan:

Kunacheva, C., Boontanon, S. K., Fujii, S., Tanaka, S., Musirat, C., Artsalee, C., \& Wongwattana, T. (2009b). Contamination of perfluorinated compounds (PFCs) in Chao Phraya River and Bangpakong River, Thailand. Water Science and Technology, 60(4), 975-982.

Kunacheva, C., Fujii, S., Tanaka, S., Boontanon, S. K., Poothong, S., Wongwatthana, T., \& Shivakoti, B. R. (2010). Perfluorinated compounds contamination in tap water and bottled water in Bangkok, Thailand. Journal of Water Supply: Research and Technology-AQUA, 59(5), 345-354. 
Lai, W. W.-P., Lin, Y.-C., Tung, H.-H., Lo, S.-L., \& Lin, A. Y.-C. (2016). Occurrence of pharmaceuticals and perfluorinated compounds and evaluation of the availability of reclaimed water in Kinmen. Emerging Contaminants, 2(3), 135-144. doi:https://doi.org/10.1016/j.emcon.2016.05.001

Lang JR, Allred BM, Field JA, Levis JW, Barlaz MA. National estimate of per-and polyfluoroalkyl substance (PFAS) release to US municipal landfill leachate. Environmental science \& technology. 2017 Feb 21;51(4):2197-205.

Langberg HA, Arp HP, Breedveld GD, Slinde GA, Høiseter Å, Grønning HM, Jartun M, Rundberget T, Jenssen BM, Hale SE. Paper product production identified as the main source of per-and polyfluoroalkyl substances (PFAS) in a Norwegian lake: source and historic emission tracking. Environmental Pollution. 2020 Dec 9:116259.

LDD. (2010). Soil information system (scale 1:25,000). from Land Development Department http://eis.Idd.go.th/Iddeis/SoilView.aspx

Li Y, Fletcher T, Mucs D, Scott K, Lindh CH, Tallving P, Jakobsson K. Half-lives of PFOS, PFHxS and PFOA after end of exposure to contaminated drinking water. Occupational and environmental medicine. 2018 Jan 1;75(1):46-51.

Martin D, Munoz G, Mejia-Avendaño S, Duy SV, Yao Y, Volchek K, Brown CE, Liu J, Sauvé S. Zwitterionic, cationic, and anionic perfluoroalkyl and polyfluoroalkyl substances integrated into total oxidizable precursor assay of contaminated groundwater. Talanta. 2019 Apr 1;195:533-42.

Menger F, Pohl J, Ahrens L, Carlsson G, Örn S. Behavioural effects and bioconcentration of per-and polyfluoroalkyl substances (PFASs) in zebrafish (Danio rerio) embryos. Chemosphere. 2020 Apr 1;245:125573.

Niu Z, Na J, Wu N, Zhang Y. The effect of environmentally relevant emerging per-and polyfluoroalkyl substances on the growth and antioxidant response in marine Chlorella sp. Environmental pollution. 2019 Sep 1;252:103-9.

Olsen GW, Mair DC, Lange CC, Harrington LM, Church TR, Goldberg CL, Herron RM, Hanna H, Nobiletti JB, Rios JA, Reagen WK. Per-and polyfluoroalkyl substances (PFAS) in American Red Cross adult blood donors, 2000-2015. Environmental research. 2017 Aug 1;157:87-95.

Pattanasuttichonlakul, J., Boontanon, N., \& Boontanon, S. K. (2014). Contamination of perfluorooctane sulfonated (PFOS) and perfluorooctanoic acid (PFOA) in air.

Poothong, S., Boontanon, S. K., \& Boontanon, N. (2012). Determination of perfluorooctane sulfonate and perfluorooctanoic acid in food packaging using liquid chromatography coupled with tandem mass spectrometry. Journal of Hazardous Materials, 205, 139-143.

Prevedouros, K., Cousins, I. T., Buck, R. C., \& Korzeniowski, S. H. (2006). Sources, fate and transport of perfluorocarboxylates. Environmental Science \& Technology, 40(1), 32-44.

Renner, R. (2001). Growing Concern Over Perfluorinated Chemicals. Environmental Science \& Technology, 35(7), 154A-160A. doi:10.1021/es012317k

Shigei M, Ahren L, Hazaymeh A, Dalahmeh SS. Per-and polyfluoroalkyl substances in water and soil in wastewater-irrigated farmland in Jordan. Science of the Total Environment. 2020 May 10;716:137057.

Shivakoti, B. R., Tanaka, S., Fujii, S., Kunacheva, C., Boontanon, S. K., Musirat, C., Seneviratne, S., \& Tanaka, H. (2010). Occurrences and behavior of perfluorinated compounds (PFCs) in several wastewater treatment plants (WWTPs) in Japan and Thailand. Journal of Environmental Monitoring, 12(6), 1255-1264.

Solo-Gabriele HM, Jones AS, Lindstrom AB, Lang JR. Waste type, incineration, and aeration are associated with per-and polyfluoroalkyl levels in landfill leachates. Waste Management. 2020 Apr 15;107:191-200.

Page $11 / 16$ 
Stoiber T, Evans S, Naidenko OV. Disposal of products and materials containing per-and polyfluoroalkyl substances (PFAS): A cyclical problem. Chemosphere. 2020 Dec 1;260:127659.

Supreeyasunthorn, P., Boontanon, S. K., \& Boontanon, N. (2016). Perfluorooctane sulfonate (PFOS) and perfluorooctanoic acid (PFOA) contamination from textiles. Journal of Environmental Science and Health, Part A, 51(6), 472-477.

Vo HN, Ngo HH, Guo W, Nguyen TM, Li J, Liang H, Deng L, Chen Z, Nguyen TA. Poly-and perfluoroalkyl substances in water and wastewater: A comprehensive review from sources to remediation. Journal of Water Process Engineering. 2020 Aug 1;36:101393.

Wang B, Yao Y, Chen H, Chang S, Tian Y, Sun H. Per-and polyfluoroalkyl substances and the contribution of unknown precursors and short-chain (C2-C3) perfluoroalkyl carboxylic acids at solid waste disposal facilities. Science of The Total Environment. 2020 Feb 25;705:135832.

Wang, F., \& Shih, K. (2011). Adsorption of perfluorooctanesulfonate (PFOS) and perfluorooctanoate (PFOA) on alumina: influence of solution pH and cations. Water Research, 45(9), 2925-2930.

Wang, T., Khim, J. S., Chen, C., Naile, J. E., Lu, Y., Kannan, K., Park, J., Luo, W., Jiao, W., Hu, W., \& Giesy, J. P. (2012). Perfluorinated compounds in surface waters from Northern China: Comparison to level of industrialization. Environment international, 42, 37-46. doi:https://doi.org/10.1016/j.envint.2011.03.023

Wei Z, Xu T, Zhao D. Treatment of per-and polyfluoroalkyl substances in landfill leachate: status, chemistry and prospects. Environmental Science: Water Research \& Technology. 2019;5(11):1814-35.

Wu Y, Miller GZ, Gearhart J, Peaslee G, Venier M. Side-chain fluorotelomer-based polymers in children car seats. Environmental Pollution. 2020 Aug 22;268:115477.

Xiao, F., Halbach, T. R., Simcik, M. F., \& Gulliver, J. S. (2012). Input characterization of perfluoroalkyl substances in wastewater treatment plants: source discrimination by exploratory data analysis. Water Research, 46(9), 3101-3109.

Xiao, F., Simcik, M. F., Halbach, T. R., \& Gulliver, J. S. (2015). Perfluorooctane sulfonate (PFOS) and perfluorooctanoate (PFOA) in soils and groundwater of a US metropolitan area: migration and implications for human exposure. Water Research, 72, 6474.

Yamashita, N., Kannan, K., Taniyasu, S., Horii, Y., Okazawa, T., Petrick, G., \& Gamo, T. (2004). Analysis of perfluorinated acids at parts-per-quadrillion levels in seawater using liquid chromatography-tandem mass spectrometry. Environmental Science \& Technology, 38(21), 5522-5528.

Yao, Y., Zhu, H., Li, B., Hu, H., Zhang, T., Yamazaki, E., Taniyasu, S., Yamashita, N., \& Sun, H. (2014). Distribution and primary source analysis of per-and poly-fluoroalkyl substances with different chain lengths in surface and groundwater in two cities, North China. Ecotoxicology and environmental safety, 108, 318-328.

Yong ZY, Kim KY, Oh JE. The occurrence and distributions of per-and polyfluoroalkyl substances (PFAS) in groundwater after a PFAS leakage incident in 2018. Environmental Pollution. 2020 Aug 10;268:115395.

\section{Figures}




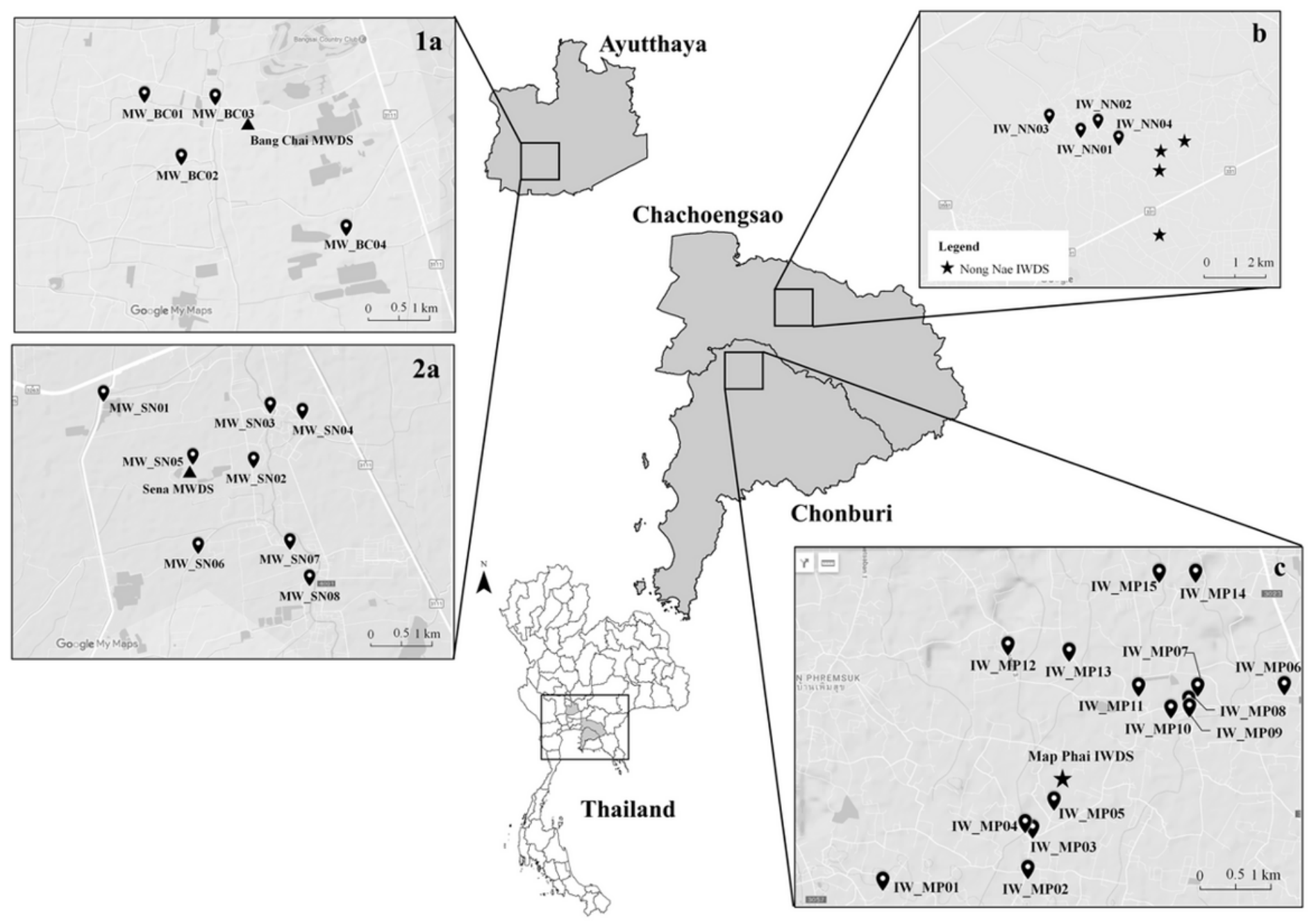

\section{Figure 1}

Groundwater sampling points in the selected study areas (1a) around Bang Sai MWDS, (2a) around Sena MWDS, (b) around Nong Nae IWDSs, and (c) Map Pai IWDS. Note: The designations employed and the presentation of the material on this map do not imply the expression of any opinion whatsoever on the part of Research Square concerning the legal status of any country, territory, city or area or of its authorities, or concerning the delimitation of its frontiers or boundaries. This map has been provided by the authors. 


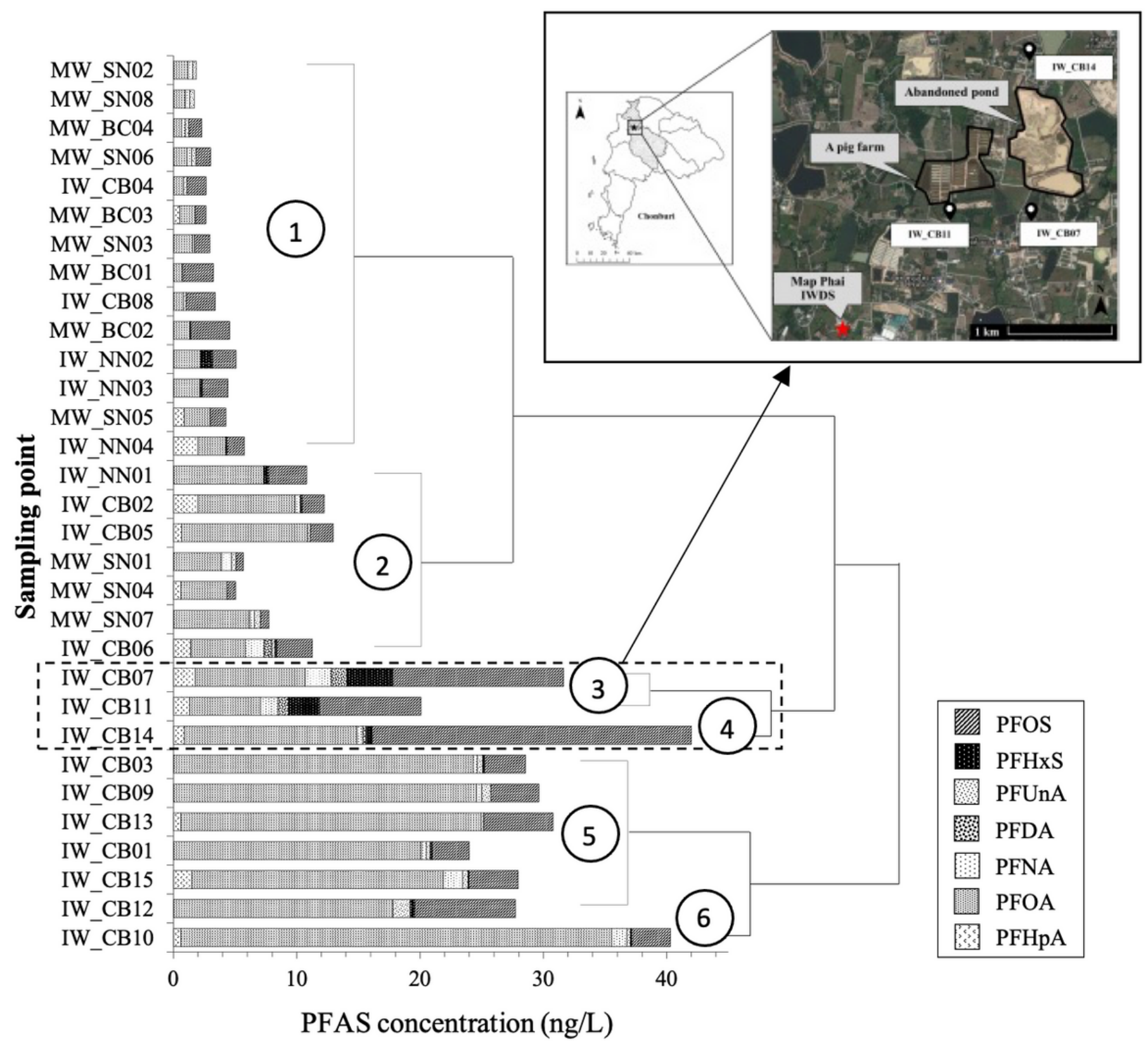

Figure 2

The dendrogram results from hierarchical cluster analysis. Note: The designations employed and the presentation of the material on this map do not imply the expression of any opinion whatsoever on the part of Research Square concerning the legal status of any country, territory, city or area or of its authorities, or concerning the delimitation of its frontiers or boundaries. This map has been provided by the authors. 

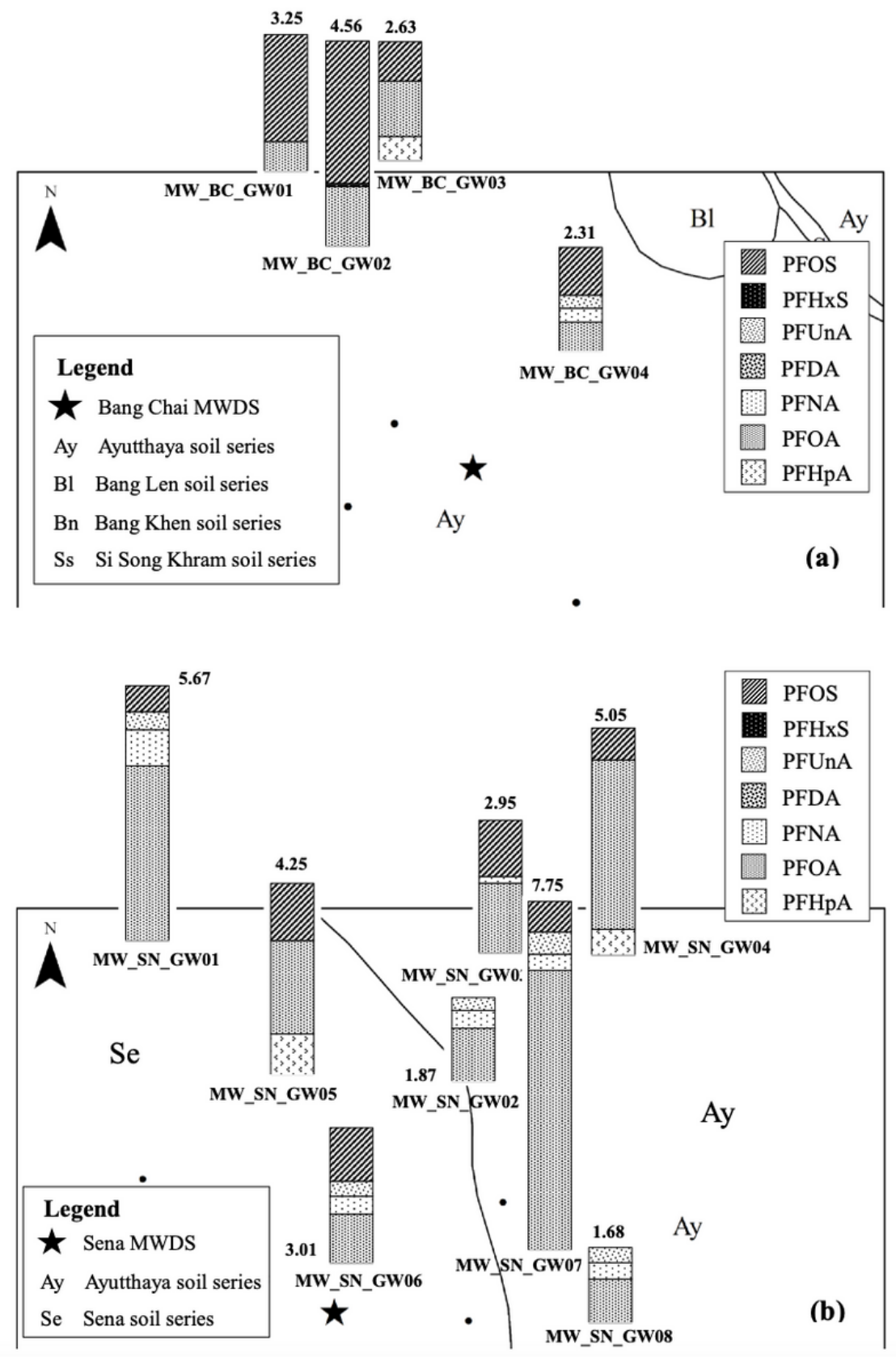

\section{Figure 3}

Map of PFAS concentration (ng L-1) around MWDSs, their distribution patterns and soil series around (a) Bang Sai MWDS, (b) Sena MWDS 


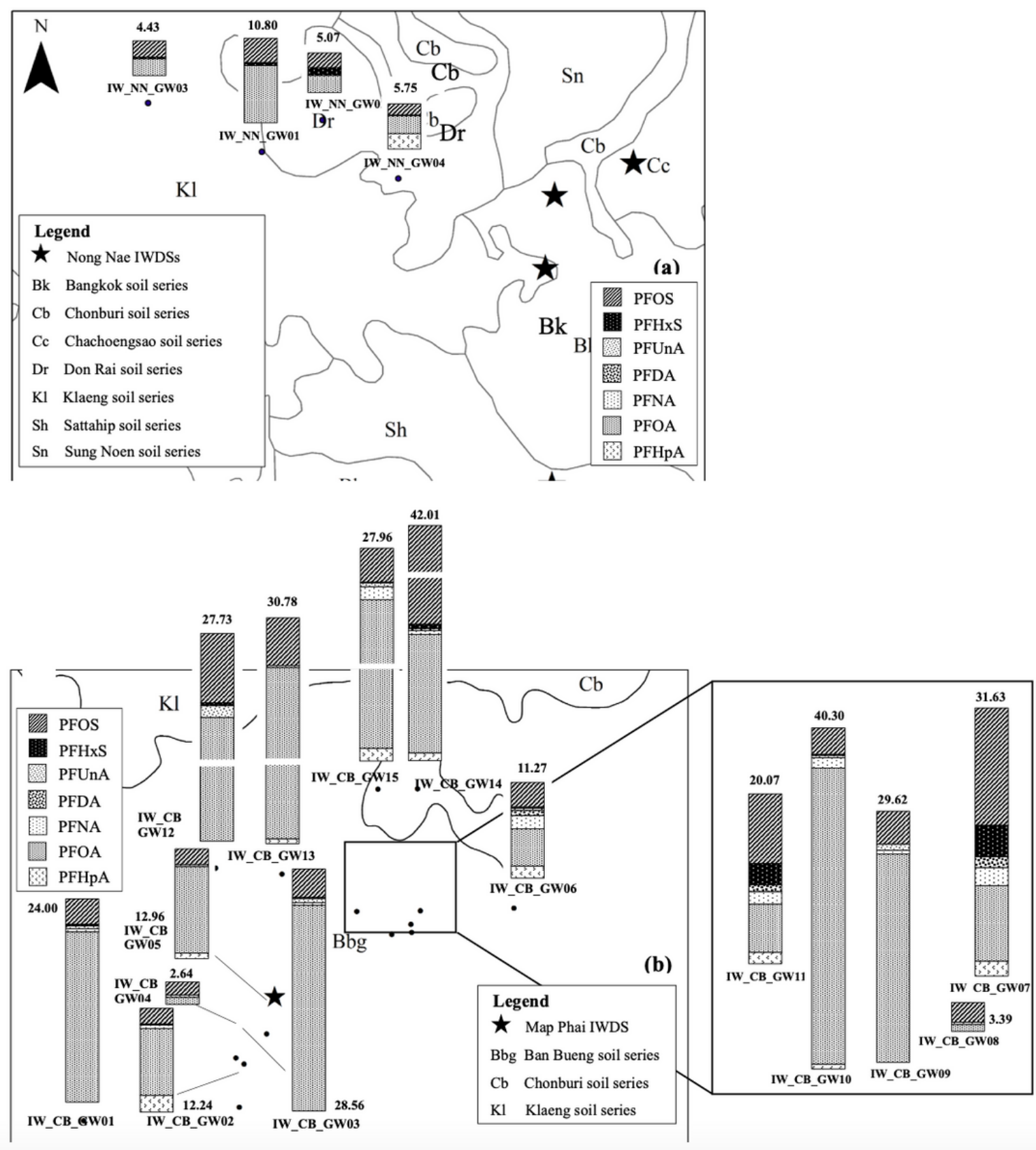

Figure 4

Map of PFAS concentration (ng L-1) around IWDSs, their distribution patterns and soil series around (a) Nong Nae IWDS, and (b) Map Pai IWDS. Note: The designations employed and the presentation of the material on this map do not imply the expression of any opinion whatsoever on the part of Research Square concerning the legal status of any country, territory, city or area or of its authorities, or concerning the delimitation of its frontiers or boundaries. This map has been provided by the authors. 